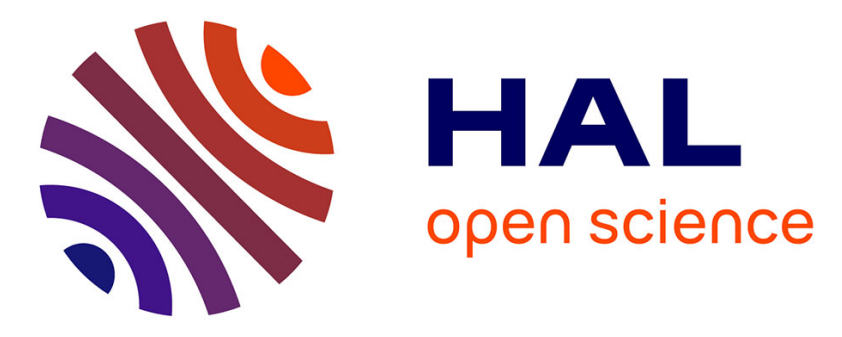

\title{
Determination of the Lesion Size in Laser-Induced Interstitial Thermal Therapy (LITT) using a Low-Field MRI.
}

Romain Viard, Aline Emptaz, Berengere Piron, Philippe Rochon, Benjamin Wassmer, Serge R. Mordon

\section{To cite this version:}

Romain Viard, Aline Emptaz, Berengere Piron, Philippe Rochon, Benjamin Wassmer, et al.. Determination of the Lesion Size in Laser-Induced Interstitial Thermal Therapy (LITT) using a Low-Field MRI.. Conference proceedings: .. Annual International Conference of the IEEE Engineering in Medicine and Biology Society. IEEE Engineering in Medicine and Biology Society. Annual Conference, 2007, 1, pp.214-7. 10.1109/IEMBS.2007.4352261 . inserm-00192852

\section{HAL Id: inserm-00192852 https://www.hal.inserm.fr/inserm-00192852}

Submitted on 29 Nov 2007

HAL is a multi-disciplinary open access archive for the deposit and dissemination of scientific research documents, whether they are published or not. The documents may come from teaching and research institutions in France or abroad, or from public or private research centers.
L'archive ouverte pluridisciplinaire HAL, est destinée au dépôt et à la diffusion de documents scientifiques de niveau recherche, publiés ou non, émanant des établissements d'enseignement et de recherche français ou étrangers, des laboratoires publics ou privés. 


\title{
DETERMINATION OF THE LESION SIZE IN LASER-INDUCED INTERSTITIAL THERMAL THERAPY (LITT) USING A LOW- FIELD MRI.
}

\author{
Romain Viard, Aline Emptaz, Bérengère Piron, Philippe Rochon, Benjamin Wassmer, Serge Mordon
}

\begin{abstract}
This study aimed to compare MR thermal mapping during Laser-induced Interstitial Thermal Therapy (LITT) to thermal lesions observed macroscopically, in order to estimate the 3D size of the coagulative necrosis. Laser irradiation was performed ex-vivo with a $980 \mathrm{~nm}$ laser in pig liver in a open low-magnetic field $(0.2 \mathrm{~T})$ scanner. The laser light was transmitted through a 1040/600 $\mu \mathrm{m}$ (outer/core diameter) bare-tip silica fiber. The laser energy was applied on a pulsed mode (10 s laser-on, 10 s laser-off) for 12 minutes, power: $6 \mathrm{~W}$, energy: $2160 \mathrm{~J}$. MR thermal mapping used T1 method for its simplicity and its efficiency at low magnetic field.
\end{abstract}

\section{INTRODUCTION}

$\mathrm{L}^{\mathrm{n}}$ iver metastasis is a major problem in public health. More often, these metastases are a consequence of primary colorectal cancer

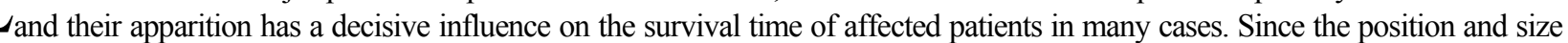
of tumors are now easily detected using imaging techniques, interstitial procedures are currently being clinically evaluated. Among them, laser-induced interstitial thermotherapy (LITT) has been recently applied for a minimally invasive technique in local treatment [1]. The technique consists in inserting a thin optical fiber inside the metastasis. Laser energy is transmitted via this optical fiber resulting in a well-defined area of coagulative necrosis. That means a destruction of tissue by direct heating, while sparing surrounding structures. Magnetic Resonance Imaging (MRI) has proven as an ideal clinical instrument for an accurate positioning of the optical fibers in the target area, for real-time monitoring of the thermal effects and for the subsequent evaluation of the extent of induced coagulative necrosis. Several MR parameters are sensitive to tissue temperature such as equilibrium magnetization, longitudinal (spinlattice) relaxation time $\mathrm{Tl}$, diffusion coefficient, and proton-resonance frequency (PRF). Due to its good temperature sensitivity at low magnetic field, its fast data acquisition and its easy post processing, thermosensitive T1-weighted MRI sequences were suggested and tested for the monitoring of hyperthermia and thermal ablations [2]. Irreversible tissue necrosis occurs with tissue temperatures in excess, so isotherms help to estimate the size of the induced lesion. Isotherms that best fit to ex-vivo macroscopic lesion may vary between $50^{\circ} \mathrm{C}$ to $60^{\circ} \mathrm{C}$ according to tissue and conditions used [3]. The expected irreversible damage zone depends on tissue parameters, applicator characteristics and laser parameters, so implementing and evaluating computer-aided thermoplanning for LITT applications remains a challenge.

This study aimed to evaluate the correlation between lesion size predicted by in situ MR monitoring and actual lesion size determined macroscopically.

\section{MATERIALS AND METHODS}

First step consisted to set up a MRI sequence. Using this sequence, the calibration in temperature is carried out so as to correlate T1 weighted signal and temperature.

\section{A. Laser deliver}

LITT was performed with a commercially diode laser unit (Pharaon 980, Osyris ${ }^{\circledR}$, Hellemmes, France). Laser light was transmitted through a bare-tip silica fiber with an outer/core diameter of 1040/600 $\mu \mathrm{m}$ (HCP 600, Sedi ${ }^{\mathbb{B}}$, Evry, France). The laser application was performed at $980 \mathrm{~nm}$ on a pulsed mode (10 sec. exposure time, $10 \mathrm{sec}$. delay between pulses), using a $6 \mathrm{~W}$ power, a total irradiation time of 12 minutes $(2160 \mathrm{~J})$.

Manuscript received April 2, 2007. Grants were awarded by the RNTS 2005 research program (ANR05RNTS01901), by the "Institut National de la Santé et de la Recherche Médicale" (U 703 Inserm), by the University Hospital of Lille, by the "Conseil Régional Nord-Pas de Calais" (CPER 2000-2006 Médecine interactive) and by the "Ministère de l'Education Nationale, de la Recherche et de la Technologie" (UPRES EA 1049).

R. Viard is with Inserm, U703, Lille, France (e-mail: r-viard@chru-lille.fr) and with LAGIS, Automatic Laboratory, USTL, France.

B. Piron is with Inserm, U703, Lille, France (e-mail: berengere.piron@voila.fr )

A. Steiner is with Nuclear Medicine, University Hospital, Lille, France (e-mail: a-steiner@o-lambret.fr )

P. Rochon is with INSERM (French National Institute of Health and Medical Research) IFR 114, Lille University Hospital, Lille, France (e-mail : philippe.rochon@lille.inserm.fr)

B. Wasmer is with Osyris SA, Hellemmes, France. (e-mail: benjamin.wassmer@osyris.com )

S. Mordon is with INSERM, IFR 114, Lille University Hospital, Lille, France (e-mail: mordon@lille.inserm.fr ) 


\section{B. Biological tissue and experimental setup}

Laser application was studied in 10 whole ex-vivo liver lobes. The liver sample was maintained at $37^{\circ} \mathrm{C}$ by a heated thermostat circulating bath. A specific holder system was developed in order to ensure good positioning of liver and laser fiber inside the MRI system. It consisted in a box with 3 holes on the top of it. Two wooden sticks were introduced in order to determine the axial plane containing the fiber guide. They were clearly identifiable on the MR images (Fig. 1) and macroscopic slices. They were used as spatial references for axial images and macroscopic measurements.

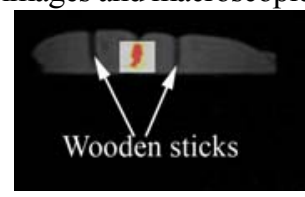

Fig. 1.

MR axial image of pig liver. Used as spatial references for axial images, two wooden sticks are clearly identifiable as hyposignal. Temperatures were calculated relative to a reference scan before treatment. Thermal maps (colors) were superimposed over the baseline morphological image (grey scale). This is representing temperature increase compared with those at the start of experiment.

\section{Macroscopic measurements}

After each laser application, the shape and extent of thermal lesion were assessed macroscopically. The liver sample was first cut along the fiber axis. This axial cut of the lesion was performed in order to measure the radius of the major axis (a) and the radius of the minor axis (b) of the necrosis (Fig. 2). This cut was chosen to correspond to the axial slice of MR thermometry. Then, a second section, perpendicular to the first one, was performed, along the axis of $b$ in order to measure the radius (c). This cut was chosen to correspond to the coronal slice of MR thermometry. Once a, b and c were measured, the volume of necrosis considered to have an ellipsoidal shape [4] was calculated as follows:

$$
\mathrm{V}=\frac{4}{3} \cdot \pi \cdot a \cdot b \cdot c
$$

Equation (1)
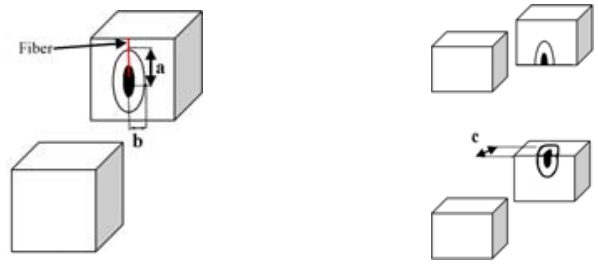

Fig. 2. Schematic drawing of the macroscopic cuts. The shape on the axial plane (I) looks like an ellipse, the shape on the coronal plane (II) is close to a circle. The black central disk represents the carbonized tissue. The black circle around represents the edge of the coagulative lesion. $\mathrm{a}, \mathrm{b}$ and $\mathrm{c}$ corresponds to the radius used in Equation (1)

\section{Magnetic Resonance Thermal mapping}

The study was carried out on an AIRIS MATE (Hitachi ${ }^{\circledR}$ Medical Co., Chiba, Japan). This 0.2 Tesla open MR Imaging system, with a panoramic Open Gantry design and permanent magnet, is highly suited for interventional MRI procedures. Its horizontal open-bore configuration (vertical magnetic field) allows simultaneous imaging and access. Receiving head coil was used.

A coronal plane was defined at a $1.5 \mathrm{~cm}$ depth from the liver surface, based on the results of previous macroscopically tests. The laser device was outside of the magnetic field in the control room. The optic fiber was introduced into an orifice created in the Faraday cage.

T1-weighted gradient-echo sequence (described below) was used to monitor local heating in different organs. However, the relation between $\mathrm{T} 1$ and temperature change with the tissue, requiring calibration for each tissue studied. Heated tissues appear as hypo-intense signal areas on T1-weighted images. This signal loss is approximated by linear relationship within a critical temperature range where necrosis occurs $[5 ; 6]$ :

$$
\Delta T=C \times \frac{\Delta S}{S_{r e f}} \quad \operatorname{avec}\left(\frac{\Delta S}{S_{r e f}}\right) \in[0 ;-1]
$$

Equation(2)

Where $\Delta \mathrm{T}$ is the temperature change measured in ${ }^{\circ} \mathrm{C} . \Delta \mathrm{S}$ represents the difference between the signal measured in the reference MR image acquired at a know temperature before the thermal treatment, $\mathrm{S}_{\mathrm{ref}}$, and the signal measured during the thermal treatment. $\mathrm{C}$ is a coefficient of temperature sensitivity, which depends on the MR device, on the sequence parameters and on the imaged tissue. 
Using this equation, no T1 mapping is required during the treatment since the temperature is deduced directly from signal changes $\Delta \mathrm{S}$ [7].

During laser heating, the dynamic analysis was carried out with the following T1-weighted gradient echo sequence : TR/TE $25 / 11.5$ $\mathrm{ms}$, FA $35^{\circ}$, NEX 4, FOV $250 \times 250 \mathrm{~mm}^{2}$, matrix $100 \times 100$, pixel size $2.5 \times 2.5 \mathrm{~mm} 2$, slice thick. $2.5 \mathrm{~mm}$, TA $10 \mathrm{sec} / \mathrm{slice}$. Two successive slices (coronal and axial) were programmed in a dynamic mode (20 sec for each couple of slices).

A calibration was done to determine experimentally the coefficient of temperature sensitivity $(\mathrm{C} \approx-0.01)$. Temperature accuracy $(2.2$ ${ }^{\circ} \mathrm{C} \pm 1.4^{\circ} \mathrm{C}$ ) between $50^{\circ} \mathrm{C}$ and $60^{\circ} \mathrm{C}$ was assessed after the calibration step. This sequence was synchronized with laser irradiation to obtain two image planes: the first one in axial plane corresponding to laser exposure $(10 \mathrm{sec})$ and the second one in coronal plane corresponding to laser intermission $(10 \mathrm{sec})$.

\section{E. Isotherms assessment}

Irreversible cellular damage usually occurs at temperatures above $50^{\circ} \mathrm{C}$ when applied for $4-6$ minutes and almost instantaneously at temperatures above $60^{\circ} \mathrm{C}$ [8]. Tissue damage affects $\mathrm{T} 1$ at temperatures greater than $40^{\circ} \mathrm{C}$. An irreversible decrease in $\mathrm{T} 1$ has been reported [9], due to alteration of macromolecule-water interactions, which occurs before the obvious proteins denaturation at $60^{\circ} \mathrm{C}$ [2]. It has been shown recently that, for both no tissue perfusion and normal tissue perfusion, the $60^{\circ} \mathrm{C}$ isotherm resembles the lesion sizes calculated using the iso-damage contours [3]. In our study, in order to assess the $60^{\circ} \mathrm{C}$ isotherm, a local segmentation was done using a semi-automatic region-growing algorithm on both planes using a house made software called Artimed ${ }^{\mathbb{B}}$ (http://www.u703.fr/). The including box of isotherms was measured automatically for each set of images (axial and coronal), to provide a, b and c radius (Fig. 3).
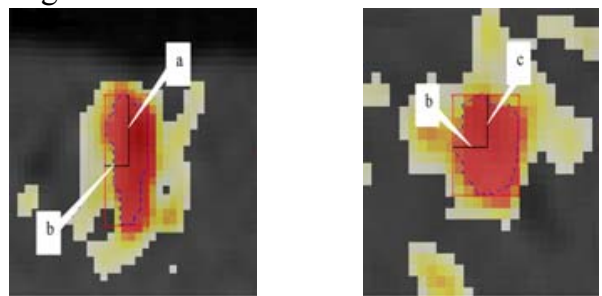

Fig. 3. MR thermal maps obtained in the axial and coronal planes. The dotted line represents the isotherm and the regular line is the including box. $\mathrm{a}, \mathrm{b}$ and $\mathrm{c}$ corresponds to the radius used in Equation (1)

\section{RESULTS}

Lesions volumes were calculated and compared with the gold standard given by macroscopic evaluations (with an uncertainty of 1 mm per radius).

TABLE I

MEASURES (MM) PERFORMED ON EX-VIVO PIG LIVER

\begin{tabular}{cccc}
\hline \hline \multirow{2}{*}{ Macroscopic measures } & & Mean & St. Deviation \\
& $\mathrm{a}$ & 9.7 & 1.7 \\
& $\mathrm{~b}$ & 6 & 0.6 \\
& $\mathrm{c}$ & 6.3 & 0.7 \\
\cline { 2 - 4 } MR measures & Volume $\left(\mathrm{mm}^{3}\right)$ & 1830 & 450 \\
& $\mathrm{a}$ & 11.3 & 1.8 \\
& $\mathrm{~b}$ & 7 & 1.0 \\
& $\mathrm{c}$ & 6.7 & 1.6 \\
\cline { 2 - 4 } & Volume $\left(\mathrm{mm}^{3}\right)$ & 1969 & 680 \\
\hline
\end{tabular}

$\mathrm{a}, \mathrm{b}$ and c corresponds to the radius used in Equation (1)

\section{A. MRI thermal mapping}

MRI thermal mapping was performed on each of the 10 lobes during laser irradiation. Figure 4 shows an example of 3 axial images obtained during laser irradiation, according to the protocol previously described. These images were obtained respectively 30 $\mathrm{s}, 320 \mathrm{~s}$ and $720 \mathrm{~s}$ after switching on the laser. This demonstrates reproducible loss of signal intensity in MRI corresponding to increasing tissue temperatures. The elliptic growth of the lesion radius (a) increased with the exposure time. This evolution was obtained for 7 lesions with a homogeneous temperature distribution. At the end of the laser irradiation, thermal maps showed systematically an ellipsoidal shape with a long axis parallel with fiber track. For 3 lobes, the vicinity of a large blood vessel led to an irregular lesion shape, and a temperature increase

mainly observed inside the vessel (Fig. 5). The presence of these vessels was confirmed by macroscopic examination (see below). Consequently, measurements and calculations were performed only on 7 lesions.

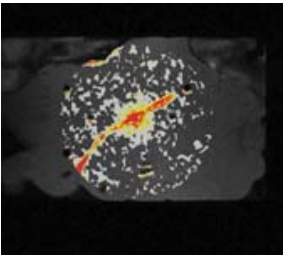

Fig. 5. Detection of a large vessel in the vicinity of the laser fiber tip. The coronal thermal map was obtained during $980 \mathrm{~nm}$ laser irradiation on a 
pulsed mode (10 s laser-on, $10 \mathrm{~s}$ laser-off) - power: $6 \mathrm{~W}$ and duration time:

$12 \mathrm{~min}$. This lesion shape diverges from the elliptical shape.

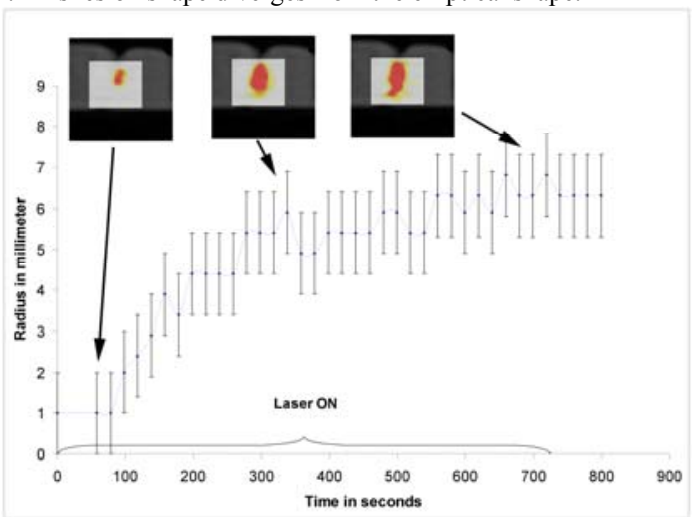

Fig. 4. Growth of the radius of the major axis (a) during a 720 seconds laser application (980 $\mathrm{nm}$ on a pulsed mode) on an ex-vivo pig liver. The lesion radius increases significantly with the exposure time. Error bars correspond to a $1 \mathrm{~mm}$ error. The size at the end of the irradiation was 6.9 $\mathrm{mm}$.

Table 1 shows the results of the volume of these lesions (MRI and macroscopic). The mean volume computed was $1969 \mathrm{~mm}^{3}$.

\section{B. Macroscopic lesion}

Among the 10 lobes, the macroscopic observation confirmed the presence of a large vessel in 3 of them. This observation corresponded to the thermal mapping (see above). For the 7 remaining lobes, two different zones were observed in the macroscopic section (Fig. 6): a dark central cavity, representing the carbonized tissue, surrounded by a white zone induced by the coagulation of the liver tissue. The lesion was systematically elliptical with the major axis along the laser applicator. The volumes of the laser-induced lesions were calculated from the three measured radius (a, b, c). The mean macroscopic volume was $1830 \mathrm{~mm}^{3}$ (table 1).

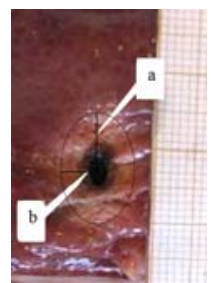

Fig. 6. macroscopic view of a cut in the plane along the laser fiber in exvivo pig liver following a laser application, (6W during 12 minutes using a $980 \mathrm{~nm}$ laser)The whitish region is the resulting area of coagulation, a and $\mathrm{b}$ are measured.

\section{Comparison between macroscopic lesions and temperature maps}

An ellipsoid morphology was visible in both cases. The mean radius estimated by $60^{\circ} \mathrm{C}$ isotherm $(\mathrm{n}=21 \mu=7.9 \pm 0.4$ median $=8$ $\sigma=2.4$ range $=[5 ; 12])$ were equivalent to the mean radius determined by macroscopic evaluation $(\mathrm{n}=21 \mu=7.8 \mathrm{~mm} \pm 0.5 \mathrm{median}=6.5$ $\sigma=2.3$ range $=[5.5 ; 12.5]$ ). It was confirmed by the slight difference between macroscopic radius and isotherm radius of $0.04 \pm 0.3 \mathrm{~mm}$ $(\sigma=1.4$ median $=-0.5$, range $=[-2.5 ; 2.7])$. The correlation between the maximal radius of the lesion visualized on thermal map at the end of the irradiation, and the maximal radius on macroscopic lesion is displayed on figure 7. The Spearman coefficient of correlation found was $0.64(\mathrm{p}<0.05)$. Assuming an error of $\pm 1 \mathrm{~mm}$, the lesion radius determined from isotherm $60^{\circ} \mathrm{C}$ is in good agreement with the macroscopic result. The mean ratio between macroscopic radius and isotherm radius was not significantly different from 1 . Figure 7 compares on each experiment, calculated volumes from isotherm radius and calculated volumes from macroscopic radius. The median difference between macroscopic volumes and isotherm volumes $\left(-66 \mathrm{~mm}^{3}\right)$ represents the volume of only 4.2 voxels $\left(2.5 * 2.5 * 2.5 \mathrm{~mm}^{3}\right)$. A Spearman test indicated that the macroscopic and isotherm volumes are correlated $\left(\mathrm{R}^{2}=0.70\right)$ significantly $(p=0.08)$. The mean ratio of $1.03 \pm 0.16$ and the median ratio of $0.97(\sigma=0.44$ range $=[0.6 ; 1.6])$ between the macroscopic volumes and the isotherm volumes demonstrate their resemblance. 


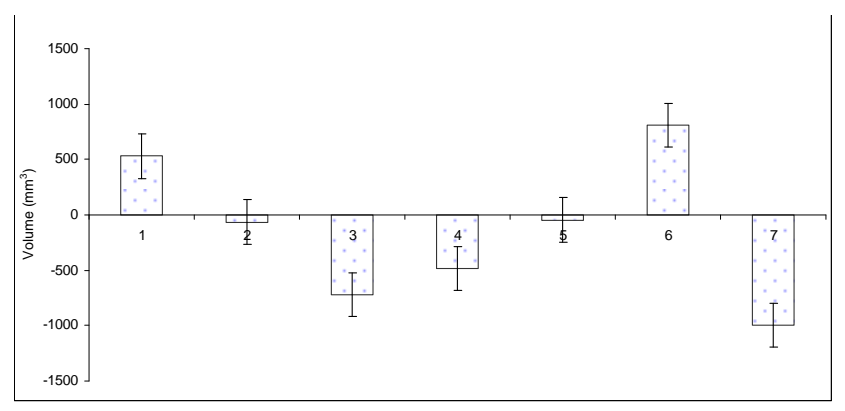

Fig. 7. Chart show difference between the macroscopic volumes (1830 $\mathrm{mm}^{3} \pm 188$ median $=1593 \sigma=499$ range $\left.=[754 ; 2657]\right)$ and the estimated volumes $\left(1969 \mathrm{~mm}^{3} \pm 257\right.$ median $=2075 \sigma=680$ range $\left.=[1282 ; 2592]\right)$, after 12 minutes energy deposition in seven ex-vivo lobes. The error bars correspond to an uncertainty of 1 millimeter on each radius.

\section{CONCLUSION}

High magnetic field system, (1.5 or 3 Tesla) have been already proposed for thermal mapping with faster scan time. However these high magnetic field systems are very expensive and relatively unsuitable for a procedure of this nature, because they are closed systems with limited access to the patient. The particular configuration of the Hitachi Airis Mate ( $0.2 \mathrm{~T}$ open field), used for our experiments, is an undeniable advantage. Non-invasive temperature measurement using MRI is based on the analysis of changes in longitudinal relaxation time (T1), diffusion coefficient (D), or water proton resonance frequency (PRF). Detailed comparisons of these methods are abundant in the literature [10] [5]. At present time, PRF is the most frequently used method, because its sensitivity is both linear to temperature and tissue independent. But PRF method is not available on low magnetic field; its sensitivity is 7 times less important at 0.2 Tesla than at 1.5 Tesla. The use of the diffusion method is restricted due to prolonged echo time and anisotropic diffusion in tissue. Both methods are not applicable in fatty tissue. T1 weighted thermal sequences permits a precise control of heat diffusion in tissue [11] [12], it is the easiest way to measure the temperature. An almost linear correlation between laser induced temperature increase and T1 signal loss in liver tissue was used. The temperature changes, between room temperature and $60^{\circ} \mathrm{C}$, could be measured suitably from the signal intensity changes in T1-weighted sequences. Continuous monitoring was enabled by means of rapid image updates; thermal mapping was displayed during therapy. Gradient Echo sequence was chosen because it provides good T1-weighting and good acquisition time. The sequence used in this study offers a good trade-off between the spatial definition (voxel volume of $15.6 \mathrm{~mm}^{3}$ ), the temperature resolution $\left(2.2^{\circ} \mathrm{C} \pm 1.4^{\circ} \mathrm{C}\right)$ and the acquisition time (TA=10 s/image). Thus, $3 \mathrm{D}$ volume estimation was updated with a temporal resolution of 20 seconds; this could be customized (e.g. in reducing NEX) in order to update faster thermal mapping, but with a loss of SNR. These results are slightly better than those obtained on systems with a comparable magnetic field. Thanks to the imaging technique used in this study, quantitative temperature monitoring with a low field 0.2 Tesla open MRI is sufficient as demonstrated by the correlation observed between lesions calculated from thermal mapping and macroscopic lesions. Laser therapy is particularly suited to MRI because laser fibers are not and do not interfere with the MR signal, whereas others localized delivery of energy (RF, acoustic etc) will interfere. Except this, the presented methods could be theoretically applied for other applications.

\section{References}

[1] T. J. Vogl, K. Eichler, S. Zangos, and M. G. Mack, "Interstitial laser therapy of liver tumors," Medical Laser Application, vol. 20, no. 2, pp. 115-118, June2005.

[2] F. A. Jolesz, "MR imaging of laser-tissue interactions," Radiology, vol. 168, no. 1, pp. 249-253, 1988.

[3] I. A. Chang and U. D. Nguyen, "Thermal modeling of lesion growth with radiofrequency ablation devices," BioMedical Engineering OnLine, vol. 3, no. 1, p. $27,2004$.

[4] C. T. Germer, D. Albrecht, C. Isbert, J. Ritz, A. Roggan, and H. J. Buhr, "Diffusing Fibre Tip for the Minimally Invasive Treatment of Liver Tumours by Interstitial Laser Coagulation (ILC): An Experimental Ex Vivo Study," Lasers in Medical Science, vol. 14, no. 1, pp. $32-39,1999$.

[5] D. Germain, P. Chevallier, A. Laurent, M. Savart, M. Wassef, and H. Saint-Jalmes, "MR Monitoring of Laser-Induced Lesions of the Liver In Vivo in a LowField Open Magnet: Temperature Mapping and Lesion Size Prediction," Imaging, vol. 13, pp. 42-49, 2001.

[6] E. A. Dick, P. Wragg, R. Joarder, M. de Jode, G. Lamb, S. Gould, and W. M. W. Gedroyc, "Feasibility of abdomino-pelvic T 1-weighted real-time thermal mapping of laser ablation," Journal of Magnetic Resonance Imaging, vol. 17, no. 2, pp. 197-205, 2003.

[7] D. Germain, E. Vahala, G. J. Ehnholm, T. Vaara, M. Ylihautala, M. Savart, A. Laurent, J. Tanttu, and H. Saint-Jalmes, "MR temperature measurement in liver tissue at 0.23 T with a steady-state free precession sequence," Magnetic Resonance in Medicine, vol. 47, no. 5, pp. 940-947, 2002.

[8] A. U. Hines-Peralta, N. Pirani, P. Clegg, N. Cronin, T. P. Ryan, Z. Liu, and S. N. Goldberg, "Microwave Ablation: Results with a 2.45-GHz Applicator in ex Vivo Bovine and in Vivo Porcine Liver1," ® RSNA, 2006, 2006.

[9] C. J. Lewa and Z. Majewska, "Temperature relationships of proton spin-lattice relaxation time T1 in biological tissues," Bull Cancer, vol. 67, no. 5, pp. 525-530, 1980.

[10] W. Wlodarczyk, M. Hentschel, P. Wust, R. Noeske, N. Hosten, H. Rinneberg, and R. Felix, "Comparison of four magnetic resonance methods for mapping small temperature changes," Phys Med Biol, vol. 44, no. 2, pp. 607-624, Feb.1999. 
[11] G. K. Eyrich, E. Bruder, P. Hilfiker, B. Dubno, H. H. Quick, M. A. Patak, K. W. Gratz, and H. F. Sailer, "Temperature mapping of magnetic resonance-guided laser interstitial thermal therapy (LITT) in lymphangiomas of the head and neck," Lasers Surg Med, vol. 26, no. 5, pp. 467-476, 2000.

[12] M. Kangasniemi, R. J. McNichols, J. A. Bankson, A. Gowda, R. E. Price, and J. D. Hazle, "Thermal therapy of canine cerebral tumors using a $980 \mathrm{~nm}$ diode laser with MR temperature-sensitive imaging feedback," Lasers Surg Med, vol. 35, no. 1, pp. 41-50, 2004. 